Filosofía en el referente: código comunicativo retórico cultural y perlocución en Zurita...

\title{
FILOSOFÍA EN EL REFERENTE: CÓDIGO COMUNICATIVO RETÓRICO-CULTURAL Y PERLOCUCIÓN EN ZURITA, DE LEOPOLDO ALAS “CLARÍN” *
}

\author{
PHILOSOPHY IN THE REFERENT: CULTURAL-RHETORIC \\ COMMUNICATIVE CODE AND PERLOCUTION \\ IN ZURITA OF LEOPOLDO ALAS "CLARÍN"
}

Tomás ALBALADEJO

Universidad Autónoma de Madrid tomas.albaladejo@uam.es

Resumen: Este artículo trata de la presencia y la función de los elementos filosóficos en el referente de las obras literarias. Se lleva a cabo un análisis de la novela corta Zurita de Leopoldo Alas "Clarín" con el fin de demostrar la relevancia de dicha función, partiendo del referente y de la intensionalización de los elementos filosóficos en la construcción de un código comunicativo retóricocultural y en el efecto perlocucionario sobre los lectores. Puesto que los elementos referenciales filosóficos son elementos culturales, en este análisis se utiliza y se prueba la perspectiva metodológica de la Retórica Cultural.

Palabras clave: Leopoldo Alas “Clarín”. Referente. Código comunicativo retórico-cultural. Retórica Cultural. Efecto perlocucionario.

Abstract: This paper deals with the presence and function of philosophical elements within the referent of literary works. An analysis of the long short story Zurita of Leopoldo Alas "Clarín" is carried out in order to demonstrate the importance of that function starting from the referent and from the intensionalisation of the philosophical elements in the construction of a cultural-rhetorical communicative code and in the perlocutionary effect on the readers. Since the philosophical referential elements are cultural ones, the methodological perspective of Cultural Rhetoric is used and tested in this analysis.

Key Words: Leopoldo Alas "Clarín". Referent. Cultural-rhetorical communicative code. Cultural Rhetoric. Perlocutionary effect.

\footnotetext{
* Este artículo es resultado de investigación realizada en el proyecto de investigación de referencia PGC2018-093852-BI00, financiado por el Ministerio de Ciencia, Innovación y Universidades.
} 
12 Tropelías. Revista de Teoría de la Literatura y Literatura Comparada, número extraordinario 6 (2020) Tomás Albaladejo

$\mathbf{I}$ En muchas obras literarias hay presencia de la filosofía. Así, en La terre de Émile Zola, en Niebla de Miguel de Unamuno, en The Last Puritan de George/Jorge Santayana, en La nausée de Jean-Paul Sartre y en muchas otras obras encontramos que el pensamiento filosófico de sus autores fundamenta las obras y en estas se manifiesta. El proceso genotextual de las obras está imbuido de las ideas de sus creadores, que llegan a formar parte del genotexto y se manifiestan en el fenotexto.

Una de las características de la literatura es su prácticamente ilimitada capacidad de representación. La obra literaria puede representar la comunicación, la realidad efectiva, la realidad imaginaria, los sueños, los deseos y otros muchos elementos y aspectos de la realidad, del mundo, entre los que se encuentra la filosofía. En este artículo no me ocupo de la participación de la filosofía del autor en el proceso genotextual de creación de la obra, sino de la incorporación al referente de la obra de la filosofía como rama del saber, de las escuelas o tendencias filosóficas, de las relaciones de los personajes con la filosofía y de todos aquellos elementos que pueden ser considerados elementos referenciales explícitamente filosóficos.

II. Zurita es una novela corta de Leopoldo Alas "Clarín" firmada en 1884 y publicada en 1886 en el volumen de cuentos y novelas cortas Pipá (Alas “Clarín”, 1886), que debe su título al primero de los relatos que contiene. Se puede considerar que Zurita es una especie de Bildungsroman, o de acuerdo con su brevedad y evitando el término Roman, una Bildungsnovelle, es decir, una novela corta de formación. El protagonista es Aquiles Zurita, que al comienzo del relato es presentado como estudiante de doctorado en la Universidad Central, pero el relato vuelve hacia atrás en el tiempo y contiene elementos referenciales previos a la situación inicial, en la que el protagonista es objeto de burla por parte de un catedrático. En la presentación de Aquiles Zurita ya aparecen referentes filosóficos en la voz narradora, que valora la actitud de aquel ante las bromas por su nombre y por su aspecto:

¡Las veces que se habrían reído de él porque se llamaba Aquiles! Ya se reía él también; y aunque siempre procuraba retardar el momento de la vergonzosa declaración, sabía que al cabo tenía que llegar, y lo esperaba con toda la filosofía estoica que había estudiado en Séneca, a quien sabía casi de memoria y en latín, por supuesto. (Alas “Clarín”, 1995a, p. 314).

El autor establece en este fragmento la índole filosófica del eje narrativo de esta novela corta, con la referencia explícita a Séneca y al conocimiento de este filósofo por el protagonista. Aquiles Zurita es presentado como una persona humilde, muy trabajadora, con una buena cultura clásica y filosófica. La burla de Zurita por el catedrático supone, a la vez que una humanización de la configuración del personaje, su situación real en un mundo en que hay quienes, antes que en sus virtudes y valores se centran en sus defectos o en sus peculiaridades. Con su bondad, con su modestia y con su esfuerzo y aplicación, el protagonista se gana el afecto de lector, en correspondencia al que por él, como corresponde al humor, siente el autor de la obra. Así, en la relación dialéctica que 
Filosofía en el referente: código comunicativo retórico cultural y perlocución en Zurita...

mantienen Zurita y el catedrático que se burla él, el lector, al igual que el autor en su desdoblamiento en narrador, se sitúa plenamente de parte del protagonista, activando, impulsado por el autor, su pathos retórico de receptor, que se transforma en una auténtica sympatheia por el singular personaje.

Las referencias a la filosofía son constantes en el texto de Zurita, con presencia de escuelas y de obras: "mas otra cosa era aborrecer al prójimo por burla de más o de menos. Esto estaba prohibido en la parte segunda de la Ética, capítulo tercero, sección cuarta” (Alas “Clarín”, 1995a, p. 315). Diferentes ramas de la filosofía como la ética, la metafísica, la estética, etc. se hallan en el referente y, por tanto, en el texto de la obra, en el que es representado. El catedrático pregunta a Zurita: "-A ver, el señor don Aquiles Zurita. [...] ¿qué entiende usted por conocimiento?” (Alas “Clarín”, 1995a, p. 315) y, ante su vacilante respuesta: "-Conocimiento... conocimiento... es... Yo he estudiado Metafísica en Valencia..." (Alas "Clarín”, 1995a, p. 316), reformula la pregunta como “-Bueno, pues... diga usted, ¿qué es conocimiento en Valencia?” (Alas Clarín, 1995a, p. 316), con previsibles consecuencias, dado el ambiente creado por el diálogo entre el profesor y el protagonista: "La cátedra estalló en una carcajada" (Alas "Clarín”, 1995, p. 316).

$\mathrm{El}$ autor ofrece unas informaciones muy completas sobre los estudios previos y las ocupaciones concretas del protagonista. Tras ayudar a su padre a dar clases de latín, se graduó como bachiller en Artes y dio clases particulares de retórica, psicología, lógica y ética. Había estudiado Notariado, pero lo que verdaderamente quería era estudiar Filosofía y Letras y hacer el doctorado. Gracias a sus ahorros, Aquiles Zurita está en Madrid como estudiante de doctorado, sin tener que ser preceptor de estudiantes ricos. Su curiosidad intelectual le lleva a intentar una constante actualización de sus conocimientos, aunque encuentra algunas dificultades: "Leía todos los libros nuevos que caían en sus manos, y se desesperaba cuando no entendía muy bien las modernas teorías" (Alas "Clarín", 1995a, p. 320). Su conocimiento de la filosofía antigua no es un obstáculo para su interés por la filosofía de su tiempo, es más bien un estímulo de su ansia por aprender.

"Clarín" plantea en su relato una visión de las corrientes filosóficas de la segunda mitad del siglo XIX que atraen a su personaje, el cual tiene tendencia a sentirse deslumbrado por las nuevas corrientes del pensamiento filosófico. El autor de La Regenta lo plantea con una dosis de humor producto de una caricaturización de dichas corrientes. El protagonista viaja a Madrid: "Llegó el día esperado con tal ansia, y Zurita entró en la corte, y antes de buscar posada, fue a matricularse en el doctorado de Filosofía y Letras" (Alas “Clarín”, 1995a, p. 322). En la pensión en la que se hospeda, Zurita conoce a don Cipriano, un filósofo krausista que le sorprende porque no lee y no estudia. Don Cipriano le anima a asistir a clases en las que no está matriculado. Y Zurita abraza el krausismo:

A los pocos días Zurita comenzaba a ser krausista como el señor don Cipriano, con quien asistía a una cátedra que ponía un señor muy triste. Sin dejar las clases en que estaba matriculado, consagró lo más y lo principal de su atención a la nueva filosofía (nueva para él) que le enseñaba el señor taciturno, con ayuda del filósofo de la posada. Don Cipriano le decía que al principio no entendería ni una palabra; que un año, y aun dos, eran pocos para comenzar a iniciarse en aquella filosofía armónica, que era la única; pero que no por eso debía desmayar, pues, como aseguraba el profesor, para ser filósofo no se necesita tener talento. Estas razones no le parecían muy fuertes a Zurita, porque ni él necesitaba tales consuelos, ni había dejado de entender una palabra de cuantas oyera al profesor. (Alas “Clarín”, 1995a, pp. 323-324). 
Don Cipriano ejerce sobre Aquiles Zurita una influencia tan fuerte que no solo lo atrae al krausismo, sino que lo disuade de hacer el doctorado y de prepararse para opositar a cátedras de universidad. La aparición de don Cipriano en la vida del protagonista produce una inflexión en las previsiones de futuro de este y la anulación de una parte importante de su submundo deseado: inmerso en el armonismo krausista, Zurita no llega a hacer los exámenes y pierde el curso en el que está matriculado para hacer el doctorado: "Sin embargo, no renegaba del armonismo, aunque por culpa de este se estaba retrasando su carrera; no renegaba porque a él debía su gran energía moral, los solitarios goces de la virtud.” (Alas “Clarín”, 1995a, p. 336).

"Clarín" no caricaturiza el krausismo ni a los krausistas en general, sino a aquellos krausistas que seguían superficialmente la filosofía de Karl Christian Friedrich Krause, sin haberla estudiado en profundidad y sin haberla asimilado en toda su entidad. Que ese krausismo mal entendido esté representado por un personaje como don Cipriano y por el profesor triste y taciturno, además de por Zurita con su facilidad para ser influenciado, sirve plenamente a la caricatura de esta filosofía. Como señala Ramos-Gascón, con ello "Clarín” no está renegando del krausismo (Ramos-Gascón, 1995, p. 96). El autor de Zurita escribe en Mis plagios: "Por lo demás, mi Zurita tiene por objeto pintar dos clases de filósofos de escalera abajo, dos ebionitas de la filosofía krausista-española, por decirlo así" (Alas “Clarín", 1888, p. 39). Pero, como he expuesto anteriormente, no es la influencia de las ideas filosóficas del autor en su obra el objeto de este artículo. Don Cipriano se va de la posada, lo cual deja a Zurita sin un mentor tan influyente, de tal modo que irá perdiendo su fe krausista para abrazar otra filosofía. Posteriormente, Zurita encuentra a don Cipriano, que lleva una vida burguesa y ha abandonado la filosofía, lo cual produce en el protagonista un desengaño personal y filosófico. Zurita se hace socio transeúnte del Ateneo y es atraído por el positivismo, influido por los médicos: "resultaba que no había más que hechos" (Alas "Clarín”, 1995a, p. 340).

El imperativo categórico kantiano es utilizado por "Clarín” para apoyar una decisión del protagonista. Así, lo incorpora al referente y al texto:

— ¿Quién me lo impide? — preguntó a la sombra de la escalera.

Y una voz que le sonó dentro de la escalera respondió:

-Te lo impide... el imperativo categórico... Haz lo que debes, suceda lo que quiera (Alas "Clarín", 1995a, pp. 342-343).

Tras abandonar los estudios de doctorado, Zurita renuncia a su proyecto de preparar oposiciones a cátedras de universidad, se decide a opositar a cátedras de instituto $\mathrm{y}$, tras varios fracasos, obtiene la cátedra de Psicología, Lógica y Ética del Instituto de Lugarucos, un pueblo costero. Su vinculación con la filosofía persiste, más allá de su dedicación profesional en el instituto, produciéndose un nuevo cambio en su orientación filosófica: "La filosofía materialista comenzó a parecerle menos antipática, y en la duda de si había o no algo más que hechos, se consagró al epicureísmo, en latín por supuesto, no en la práctica." (Alas “Clarín”, 1995a, pp. 342-343).

En la tranquilidad de su vida en Lugarucos, Zurita se aparta de las ideas filosóficas y surge en él una pasión por el pescado y el marisco, de tal modo que llega a adquirir fama culinaria como experto en calderetas. Zurita llega a un eclecticismo filosófico que es parodiado por el autor: "en el fondo de 
Filosofía en el referente: código comunicativo retórico cultural y perlocución en Zurita...

su alma, siempre había suspirado por la armonía del análisis y de la síntesis, de Tula y la virtud, de la fe y la razón, del krausismo y los médicos del Ateneo" (Alas “Clarín”, 1995a, p. 354).

El final del relato contiene la relativización de las ideas filosóficas del protagonista. Una expresión clave en esta novela corta es "Mientras estaba en su sano juicio nunca hablaba de filosofía, ni tal vez pensaba en ella. En cátedra explicaba como una máquina la Psicología oficial, la del texto, pero nada más; le parecía hasta mala educación mentar las cuestiones metafísicas" (Alas "Clarín", 1995a, p. 354). En cambio, hablaba de filosofía cuando había bebido más de la cuenta: "y Aquiles interrumpía sus reminiscencias de filósofo idealista para dormir debajo de la mesa la borrachera de los justos" (Alas “Clarín”, 1995a, p. 354). La contraposición que hace "Clarín” entre el Zurita cuerdo y el Zurita que no está en su sano juicio, el Zurita ebrio, se extiende macroestructuralmente desde las páginas finales del relato al conjunto de este. Como don Quijote, Zurita muere cuerdo y, en la última etapa de su vida, solamente habla de filosofía cuando no está cuerdo, cuando está bajo los efectos de la bebida que ha acompañado a la caldereta que él mismo ha cocinado. El autor opone en la novela corta Zurita dos realidades del protagonista: la del peculiar filósofo que en su ingenuidad es capaz de seguir con intensa adhesión diferentes corrientes filosóficas y la del personaje que es feliz con su vida cotidiana en un apartado lugar como es Lugarucos. El propio Zurita es consciente de las dos facetas de su actividad, que son propiamente dos facetas de su vida, y las separa, como demuestra el diálogo siguiente que mantienen sus amigos en la sobremesa de una de las comidas:

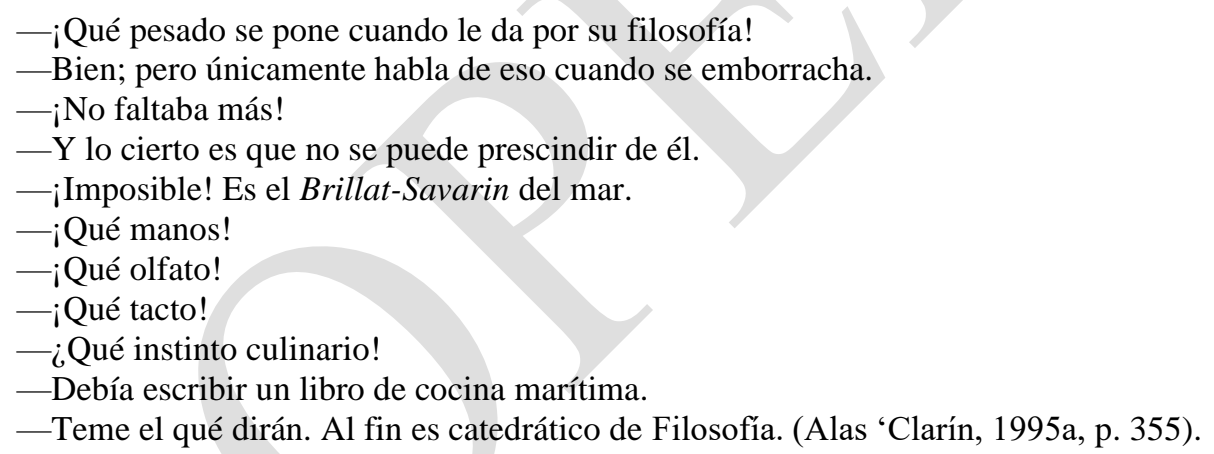

Zurita distingue lo que puede hacer y lo que no puede hacer: en su cordura tiene un lugar el pudor, es consciente de que su cátedra le impide escribir sobre cocina.

Su actividad culinaria es lo que termina por prevalecer. El relato termina así:

Ya hace años que murió Zurita, y en Lugarucos cada vez que se trata de comer pescado, nunca falta quien diga:

— ¿Se acuerdan ustedes de las calderetas de aquel catedrático de Psicología y Lógica?

- iAh, Zurita!

— iEl gran Zurita!

Y a todos se les hace la boca agua. (Alas 'Clarín, 1995a, p. 355).

Con un humor no exento de acidez, "Clarín" no sitúa el triunfo y la felicidad del protagonista en la filosofía, en lo que fue su pasión intelectual y su guía profesional, sino en la vida placentera de un pueblo de la costa, en el que durante años será recordado elogiosamente por el acierto culinario de sus calderetas. 
III. Leopoldo Alas ha incorporado la filosofía al referente de su obra Zurita y, por medio de un proceso poiético de intensionalización, es decir de transformación del referente o extensión en intensión en el texto (Albaladejo, 1990; 1992, pp. 27-31), la ha hecho parte imprescindible de un texto que carecería de sentido sin la función literaria de carácter narrativo de los elementos filosóficos tanto en el ámbito semántico-extensional como en el semántico-intensional de la obra. Estos elementos filosóficos, que son elementos del contenido, tienen, además, un papel imprescindible en el desarrollo narrativo en tanto en cuanto están situados en la evolución de los submundos del mundo de personaje del protagonista, dentro de una dinámica que actúa principalmente en su submundo real efectivo, su submundo deseado y su submundo creído, como he estudiado en otro lugar (Albaladejo, 1998).

Los elementos filosóficos hacen del referente y del resultado textual de su intensionalización una construcción literaria provista de una extraordinaria fuerza perlocucionaria. Esta fuerza tiene su origen en el macroacto de habla locucionario por el que el autor construye el referente y el texto y también por el macroacto de habla ilocucionario por el que crea una obra en la que expresa sus conocimientos de filosofía y los establece como base de la configuración del protagonista y como impulso del desarrollo narrativo. Estos dos macroactos, enraizados en la construcción referencial y su intensionalización y en la instancia productora o creadora, es decir, en el autor, se dirigen en el espacio comunicativo literario al lector, a la perlocución en la instancia receptora, en la que tienen el efecto que corresponde al macroacto de habla perlocucionario por el que el lector se ve implicado en un análisis, en un examen, en una revisión, en un recuerdo de las corrientes filosóficas que aparecen en el relato, tanto en el caso de aquellas a las que se adhiere Aquiles Zurita, las cuales, por ello, tienen una mayor implantación en la obra, como en el caso de las que aparecen de manera puntual: el estoicismo o la filosofía kantiana.

La proyección de la fuerza locucionaria y de la fuerza ilocucionaria en la fuerza perlocucionaria hace que el receptor se sienta implicado por sus conocimientos filosóficos o por su familiaridad con las corrientes filosóficas que hay en la obra, en el referente y en el texto y que no solo son necesarias para la configuración literaria del personaje y para la narratividad de la obra, sino también para establecer una conexión comunicativa y cultural entre la instancia productora y la instancia receptora por medio de la obra. Se trata de una conexión poiético-interpretativa que desde la obra sostiene la comunicación literaria de esta. Esta conexión une las dos instancias de la comunicación y hace posible en esta novela corta el funcionamiento literario de las corrientes filosóficas, situándolas en un lugar preeminente en el eje de su narratividad, la cual no habría podido desarrollarse ni consolidarse sin la información sobre las corrientes que están en relación con la vida, las aspiraciones y la personalidad de Aquiles Zurita.

La presencia de elementos filosóficos en el referente y, a partir de este, en el texto es lo que hace posible el establecimiento de un código comunicativo retórico-cultural (Albaladejo, 2016, pp. 22 y ss.; 2019) inserto en la obra, que es activado inicialmente por el autor, que es quien lo crea, y posteriormente por cada lector en su propio acto de lectura. Se trata de un código de carácter semánticoextensional, construido por los elementos culturales que hay en el referente; este código es, como todo 
el referente, objeto de un proceso de intensionalización, por el que es transformado en intensión textual, en significado textual que forma parte del texto literario y es expresado por la manifestación textual, es decir, por la superficie textual.

El código comunicativo retórico-cultural, al ser activado interpretativamente por el lector en su acto de lectura, enlaza la instancia receptora con la instancia productora, con el autor, vinculando al enlace o conexión que se establece los elementos culturales que habían sido activados por el autor en su proceso de creación de la obra literaria. Para el funcionamiento adecuado de este código es necesario que el lector posea los conocimientos pertinentes para identificar el código, aprehenderlo, activarlo y utilizarlo interpretativamente con el fin de reconstruir en su proceso de recepción e interpretación del texto literario el referente constituido por el autor. El autor cuenta con la capacidad del receptor para recuperar el código a partir del texto literario. Esta recuperación del código por el receptor implica la proyección de los macroactos locucionarios e ilocucionarios en una fuerza perlocucionaria que actúa sobre el lector, haciendo que este se vincule interpretativamente al contenido filosófico de la obra, asî como a su contenido general.

Es precisamente esta implicación perlocucionaria la que consolida la dimensión retórico-cultural de los elementos filosóficos como elementos culturales, ya que son proyectados comunicativamente por la instancia productora a la instancia receptora con la finalidad de implicar perlocucionariamente al lector en el código comunicativo retórico-cultural, el cual le permite acceder a los elementos culturales del referente, identificarlos e interpretarlos y hace posible que estos produzcan un efecto en él como destinatario de la obra. La dimensión retórico-cultural de la presencia de la filosofía en el referente, y a partir de este en el texto de la obra literaria, es clave en la configuración de la Retórica Cultural (Albaladejo, 2013; 2016; Chico Rico, 2015; Fernández Rodríguez, 2019; Gallor Guarín, 2019; Gómez Alonso, 2017; Jiménez, 2015; Martín Cerezo, 2017) como parte de la Retórica y asimismo de los Estudios de la Cultura (Studies in Culture) que se ocupa del estudio de la proyección comunicativa de contenidos culturales en el discurso y en la obra literaria con la finalidad de conseguir una perlocución de carácter persuasivo y/o convincente.

IV. La filosofía en el referente tiene una característica que a la vez la diferencia y la asemeja a otros elementos que son incorporados a los referentes. La filosofía se incorpora al referente como elemento referencial discursivo, del mismo modo que se incorpora referencialmente la literatura. Filosofía y literatura son construcciones discursivas, pues tienen una realidad que es sostenida por los textos o discursos filosóficos y literarios. Así, la filosofía krausista presente en Zurita está sostenida por las obras de Krause y de varios autores. A diferencia de otros elementos referenciales, los elementos filosóficos (también los literarios) son elementos referenciales y también metarreferenciales, ya que representan construcciones referenciales de otras construcciones referenciales. Este carácter metarreferencial potencia sus efectos perlocucionarios, ya que estos son impulsados y producidos por elementos referenciales culturales que, a su vez, remiten a otros referentes, como pueden ser las obras filosóficas. Los elementos culturales del referente que están formados por ideas que proceden de obras 
filosóficas no hacen sino reforzar el código comunicativo retórico-cultural, intensificando su potencialidad de conexión comunicativa y de proyección de la fuerza locucionaria e ilocucionaria en el efecto perlocucionario para implicar a los receptores en la obra filosófica o, como es el caso de la novela corta Zurita, en la obra literaria cuyo referente contiene elementos culturales de carácter filosófico.

Esta característica abre las puertas a una revisión de las relaciones de interdiscursividad (Albaladejo, 2005), al implicar las relaciones entre elementos referenciales y discursos que forman parte de un mismo referente. Sin duda, se trata de una relación metadiscursiva, pero que también es interdiscursiva en la medida en que se produce un diálogo entre las ideas y los discursos subyacentes. Es el caso de la relación entre las ideas krausistas de don Cipriano y los textos de Krause que fundamentan el krausismo. Esta interdiscursividad de raíz metadiscursiva tiene una dimensión retórico-cultural asociada a la dimensión cultural y perlocucionaria (persuasiva, convincente) que tienen los exempla retóricos como pruebas artificiales en la argumentación retórica. En la reconstrucción de esta interdiscursividad desempeña una importante función el código comunicativo retórico-cultural, con el que los elementos referenciales filosóficos se vinculan en la creación de la obra literaria que es Zurita y en su recepción e interpretación por los lectores.

\section{Referencias bibliográficas}

Alas “Clarín”, L. (1886). Pipá. Madrid: Librería de Fernando Fé, pp. 369-441; en http://biblioteca digital.jcyl.es/i18n/consulta/registro.cmd?id=14310 (recuperado el 20 de marzo de 2020).

Alas “Clarín”, L. (1888). Mis plagios. Madrid: Librería de Fernando Fé; en https://bibliotecadigital. jcyl.es/es/consulta/registro.cmd?id=14267 (recuperado el 20 de marzo de 2020).

Alas “Clarín”, L. (1995a). Zurita. En Alas “Clarín” (1995b): 313-355.

Alas “Clarín”, L. (1995b). Pipá, edición de Antonio Ramos-Gascón. Madrid: Cátedra, 12. a edición. AlbAladeJo, T. (1990). Semántica extensional e intensionalización literaria: el texto narrativo. Epos, 6: $303-314$.

AlBALAdEJO, T. (1992). Semántica de la narración: la ficción realista. Madrid: Taurus.

AlBAladeJo, T. (1998). Teoría de los mundos posibles y macroestructura narrativa. Análisis de las novelas cortas de Clarín. Alicante: Universidad de Alicante, reedición.

Albaladejo, T. (2005). Retórica, comunicación, interdiscursividad. Revista de Investigación Lingüística, 8: 7-33.

Albaladejo, T. (2013). Retórica cultural, lenguaje retórico y lenguaje literario. Tonos. Revista de Estudios Filológicos, 25, en https://www.um.es/tonosdigital/ znum25/secciones/estudios-03retorica_cultural.htm (recuperado el 15 de febrero de 2020).

Albaladejo, T. (2016). Cultural Rhetoric. Foundations and Perspectives. Res Rhetorica, 3(1): 1-27, DOI: https://doi.org/10.17380/rr2016.1.2

Albaladejo, T. (2019). The Pragmatics in János S. Petőfi's Text Theory and the Cultural Rhetoric: The Extensional-Semantic Code and the Literature of the Spanish Golden Age, en M. 
Filosofía en el referente: código comunicativo retórico cultural y perlocución en Zurita...

Borreguero Zuloaga y L. Vitacolonna (Eds.), The Legacy of János S. Petöfi. Text Linguistics, Literary Theory and Semiotics (pp. 92-109). Newcastle upon Tyne: Cambridge Scholars Publishing: 92-109.

Chico Rico, F. (2015). La Retórica Cultural en el contexto de la Neorretórica. Dialogía. Revista de Lingüística, Literatura y Cultura, 9: 304-322; en https://www.journals.uio.no/index.php/ Dialogia/article/view/2597 (recuperado el 15 de febrero de 2020).

FERNÁNDEZ RODRÍGUEZ, M. A. (2019). Transcreación. Retórica cultural y traducción publicitaria. En Castilla. Estudios de Literatura, 10: 223-250, DOI: https://doi.org/10.24197/cel.10.2019.223$\underline{250}$

Gallor Guarín, J. O. (2019). El "Diálogo de Doctrina Christiana” de Juan de Valdés. Retórica cultural, discurso y literatura. Alicante: Universidad de Alicante.

Gómez Alonso, J. C. (2017). Intertextualidad, interdiscursividad y Retórica Cultural. Tropelías. Revista de Teoría de la Literatura y Literatura comparada, 1 (Homenaje a José Enrique Martínez): 107-115, DOI: https://doi.org/10.26754/ojs_tropelias/tropelias.201712104

JiMÉNEZ, M. (2015). En torno al desarrollo de la semiótica literaria y el concepto de cultura. En Dialogía. Revista de Lingüística, Literatura y Cultura, 9: 208-229; en https://www.journals.uio. no/index.php/Dialogia/article/view/2594/2306 (recuperado el 15 de febrero de 2020).

MARTín CEREZO, I. (2017). La Retórica cultural y los discursos en las obras literarias: El mercader de Venecia de William Shakespeare. Actio Nova. Revista de Teoría de la Literatura y Literatura Comparada, 1: 114-136; en https://revistas.uam.es/index.php/actionova/article/view/8574 (recuperado el 15 de febrero de 2020).

RAMOS-GASCÓN, A. (1995). Introducción. En AlAS “CLARÍN” (1995b): 15-97. 